lý xã hội và tỉnh thần mà bệnh nhân và gia đình họ phải chịu đựng. Nhu câu chăm sóc giảm nhẹ sẽ càng tăng cao do hệ quả nối tiếp của già hóa dân số và sự gia tăng tân suất mắc các bệnh NCDs. Điều này phù hợp với nghiên cứu của chúng tôi khi $73 \%$ NCT có nhu cầu chăm sóc tại nhà.

4.2.5. Nhu cầu Phưc hồi chức năng. Người cao tuổi là đối tượng dễ tổn thương đối với bệnh tật và các loại chấn thương. Việt Nam đang bước vào giai đoạn già hóa dân số, với khoảng 11 triệu người cao tuổi, do đó nhu cầu phục hồi chức năng rất cao. Trong nghiên cứu của chúng tôi, nhóm bệnh tim mạch như tăng huyết áp, đột quy, đau thắt ngực chiếm tỷ lệ cao bên cạnh các vấn đề về cờ xương khớp. Và những chấn thương này đòi hỏi quá trình điều trị kéo dài, đi kèm với đó là quá trình phục hồi chức năng tại các CSYT hoặc tại nhà.

4.2.6. Nhu câu Chăm sóc NCDs. Ở nghiên cứu này, có $63,7 \%$ NCT mong muốn nhận được các dịch vụ chăm sóc các bệnh mạn tính. Kết quả cũng cho thấy các bệnh THA, đái tháo đường rối loạn chuyển hóa... chiếm tỷ trọng lớn trong cơ cấu bệnh tật của đối tượng nghiên cứu.

\section{KẾT LUẬN}

Nghiên cứu cho thấy mức độ suy giảm một số chức năng phổ biến và tình trạng khuyết tật ở NCT như ghi nhớ, nhìn, nghe, đi lại. Kết quả cho thấy nhu câu CSSK của NCT ở các khía cạnh thể chất, tinh thần và xã hội, góp phần cung cấp một bức tranh chung về thực trạng và nhu cầu sức khỏe của NCT trên 3 vùng sinh thái ở tỉnh TTH. Nghiên cứu đã phản ánh rõ nét xu hướng già hóa dân số hiện nay và vai trò quan trọng của dịch vụ CSSK người cao tuổi, phù hợp với bối cảnh văn hóa Việt Nam, nên được ưu tiển và đầu tư hơn nữa trong thời gian đến.

\section{TÀI LIÊU THAM KHẢO}

1. Hoàng Trung Kiên, Nguyễn Duy Luật, Hoàng Văn Tân (2013), "Nghiên cứu nhu cầu, đáp ứng dịch vụ chăm sóc sức khỏe người cao tuổi và thứ nghiệm mô hình can thiệp cộng đồng tại huyện Đông Anh, Hà Nội", Tạp chí y học dự phìng. 7, tr.143.

2. Burman J., et al (2019), "Assessment of Poor Functional Status and its Predictors among the Elderly in a Rural Area of West Bengal", ] Midlife Health. 10(3), pp. 123-130

3. Ji Y., et al (2015), "Prevalence of dementia and main subtypes in rural northern China", Dementia and qeriatric coqnitive disorders. 39(5-6), pp. 294-302.

4. Bana, K. S., Tak, S. H., Oh, J., Yi, J., Yu, S. Y., \& Truna, T. O. (2017) "Health status and the demand for healthcare amona the elderly in the rural Ouoc-Oai District of Hanoi in Vietnam", BioMed research international, 2017.

5. Langa K. M., et al (2017), "A comparison of the prevalence of dementia in the United States in 2000 and 2012", JAMA internal medicine. 177(1), pp. 51-58.

6. Storeng S. H., Sund E. R. and Krokstad S. (2018), "Factors associated with basic and instrumental activities of daily living in elderly participants of a population-based survey: the Nord-Trøndelag Health Study, Norway", BMJ Open. 8(3), p. e018942.

7. Weden, M. M., Shih, R. A., Kabeto, M. U., \& Langa, K. M. (2018), "Secular trends' in dementia and cognitive impairment of US rural and urban older adults", American journal of preventive medicine. 54(2), pp. 164-172.

8. WHO (2000), WHO Regional Office for the Western Pacific Regional guidelines for developing a healthy cities project, WHO Regional Office for the Western Pacific, Manila

\title{
ẢNH HƯỞNG CỦA LỆCH ĐƯỜNG GIỮA ĐẾN THẨM MỸ NỤ CƯờI
}

\section{Nguyễn Thị Bích Ngọc*, Quách Thị Thuý Lan*, Phan Quân*}

\section{TÓM TẮT}

Nghiên cứu mô tả cắt ngang nhằm đánh giá mức độ lệch đường giữa răng có thể nhận biết được bởi người không chuyên môn làm ảnh hưởng đến thẩm mỹ nụ cười. Ảnh chụp nụ cười đẹp được điều chỉnh trên máy tính cho lệch đường giữa sang phải và trái với biên độ lệch tăng dân từ 1 đến 4 mm. 50 người không chuyên môn được lựa chọn để đánh giá nụ cười

*Viện Đào tạo Răng Hàm Mặt

Chịu trách nhiệm chính: Nguyễn Thị Bích Ngọc

Email: bichngoc@hmu.edu.vn

Ngày nhận bài: 19.11.2020

Ngày phản biện khoa họ: 28.12.2020

Ngày duyệt băi: 7.01.2021 đã được chỉnh đường giữa trên cùng một máy tính. Kết qủa: Đường giữa lệch $>2,98 \pm 0,78 \mathrm{~mm}$ sẽ làm cho nụ cười mất thẩm mỹ. Nam giới chấp nhận lệch đường giữa $3,02 \pm 0,8 \mathrm{~mm}$, nữ $2,94 \pm 0,79 \mathrm{~mm}$. Sự khác biệt này không có ý nghĩa thống kê với $p>0,05$.

\section{SUMMARY \\ IMPACTION OF DENTAL MIDLINE DEVIATION TO ESTHETIC SMILE}

This cross- section study aims to evaluate the threshold of lay people's esthetic perception of dentition midline deviation. The dental midline of an esthetic smile photo was altered digitaly to shift to the left and right from 1 to $4 \mathrm{~mm}$. The images then were evaluated by 50 lay persons to determine the threshold for acceptable midline deviation and factors 
influencing perception. Results: The mean value for the threshold above which a deviation was judged "unesthetic smile" was 2,98 $\pm 0,78 \mathrm{~mm}$. Man and woman perception are 3,02 $\pm 0,8 \mathrm{~mm}$ and 2,94 $\pm 0,79 \mathrm{~mm}$ respectively. There was no statistically difference $(p>$ 0.05 ) between man and woman perception.

\section{I. ĐĂT VẤN ĐỀ}

Thẩm mỹ nụ cười bị hưởng bởi sự hài hoà và cân xứng của các cấu trúc như răng, môi, ngách hành lang má, mô mềm. Vì vậy đánh giá sự cân xứng nụ cười rất quan trong trong đoán chỉnh nha [1]. Trong điều trị chỉnh nha, thường gặp đường giữa răng hàm trên và hàm dưới bị lệch, nguyên nhân có thể do lêch lac răng hay xướng. Phụ thuộc vào từng trường hợp cụ thể mà đôi khi điều chỉnh lại lệch đường giữa có thể đòi hỏi một quá trình chỉnh nha phức tạp không tương xứng với lợi ích bệnh nhân đạt được.

Điều trị những trường hợp bất cân xứng thường rất khó khăn và kéo dài thời gian điều trị. Có rất nhiều các nghiên cứu về vấn đề chẩn đoán và điều trị lệch đường giữa [2],[3] nhưng lại không có nhiều nghiên cứu về tầm quan trọng thẩm mỹ của nó và câu hỏi đặt ra đó là có thể chấp nhận lệch đường giữa ở mức độ nào để không ảnh hưởng đến thấm mỹ. Vì vậy mục tiêu của nghiên cứu này nhằm nghiên cứu cảm nhận của người không có chuyên môn về ảnh hưởng của lệch đường giữa hàm trên đối với thẩm mỹ nụ cười.

\section{II. ĐỐI TƯỢNG VÀ PHƯƠNG PHÁP NGHIÊN CỨU 1. Đối tượng nghiên cứu.}

Ảnh chụp kỹ thuật số nụ cười xã giao đen trắng (posed smile) [4] được hội đồng chuyên gia thẩm mỹ lựa chọn là đẹp.

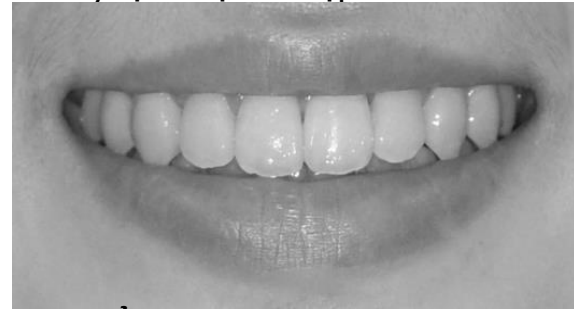

\section{Hình 2.1: Ảnh chupp nu cười được lựa chọn trong nghiên cứu}

Từ ảnh chụp ban đầu, dùng phần mềm Adobe Photoshop CS5 để điều chỉnh đường giữa hàm trên lệch sang trái/phải tăng dần, mỗi ảnh lệch thêm $1 \mathrm{~mm}$, từ $1 \mathrm{~mm}$ đến $4 \mathrm{~mm}$. Đường giữa hàm dưới và cung Cupidon được cố định để làm mốc tham chiếu.
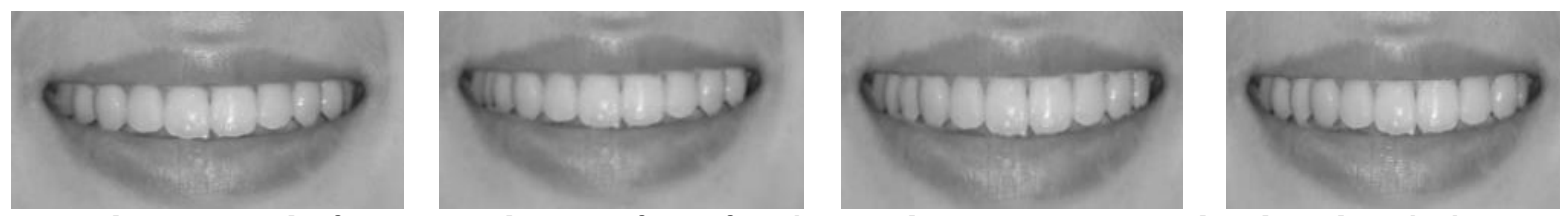

Hình 2.2: Các ảnh nụ cười đã chỉnh sưa lệch đường giữa sang trái với mức độ lệch $1 \mathrm{~mm}, 2 \mathrm{~mm}$, 3mm và $4 \mathrm{~mm}$.
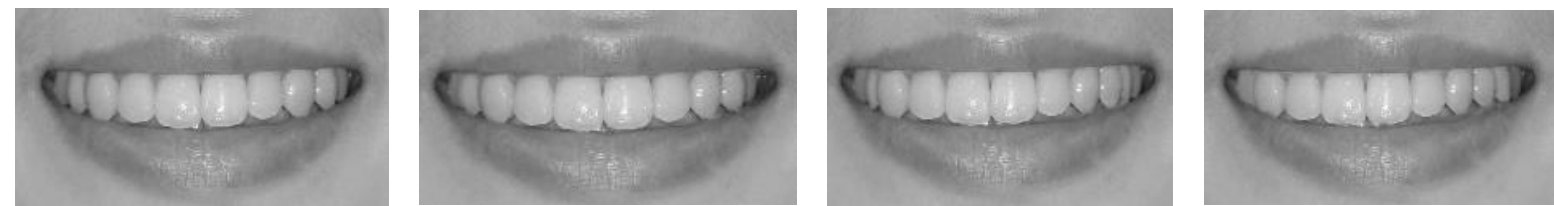

Hình 2.3: Các ảnh nụ cười đã chỉnh sưa lệch đường giữa sang phải với mức độ lệch $1 \mathrm{~mm}, 2 \mathrm{~mm}, 3 \mathrm{~mm}$ và $4 \mathrm{~mm}$

50 người nhà bệnh nhân tại Bệnh viện Đại học $\mathrm{Y}$ Hà Nội trong độ tuổi từ 25-55 tuổi tham gia nghiên cứu với tiêu chuẩn lựa chọn:

- Là người Việt Nam.

- Hai mắt có thị lực bình thường.

- Không có kiến thức chuyên ngành Răng Hàm Mặt.

Các đối tượng thực hiện đánh giá một bộ ảnh nụ cười đã được chỉnh đường giữa trên cùng môtt máy tính. Mỗi người có 10 giây để đánh giá mối ảnh, và chọn ra ảnh đầu tiên cảm thấy xâu.

\section{Phân tích số liệu}

- Nhập số liệu sử dụng phần mềm Excel, Các số liệu đo được xử lý theo phương pháp thống kê y học trong chương trình SPSS 20.0, sử dụng T-test để kiểm định sự khác biệt giữa các biến định lượng.

Kiểm soát sai số: Giải thích, tư vấn, hướng dẫn đầy đủ các đối tượng tham gia đánh giá trước khi nghiên cứu. Thống nhất mọi đối tượng đều đánh giá trên cùng một máy tính. Màn hình máy tính để ở cùng chế độ phân giải, sáng tối, tương phản.

5. Đạo đức nghiên cứu. Nghiên cứu được thực hiện dựa trên sư đồng ý từ phía đối tượng nghiên cứu. Đảm bảo các thông tin của đối 
tượng nghiên cứu được giữ bí mật. Nghiên cứu chỉ nhằm bảo vệ và nẩng cao sức khỏe cho cộng đồng, không nhằm một mục đích nào khác.

\section{KẾT QUẢ NGHIÊN CỨU}

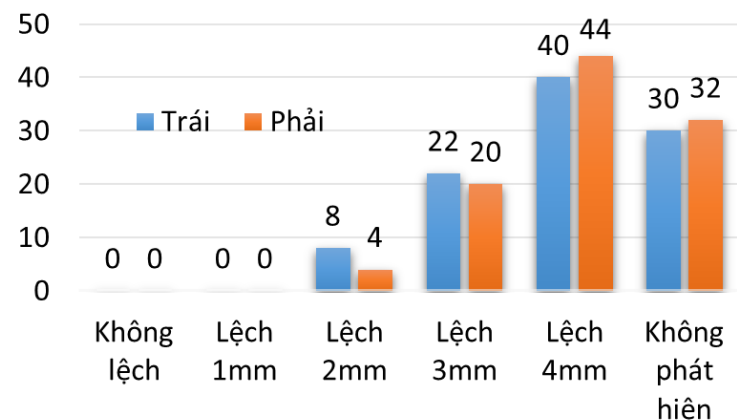

Biểu đồ 1: Tỷ lệ phát hiện nụ cười không đẹp khi chinh lệch đường giứa theo từng mức độ.

Nhận xét: Tỷ lệ phát hiện nụ cười mất thẩm mỹ khi lệch đường giữa $4 \mathrm{~mm}$ là cao nhất lần lượt là lệch trái $4 \mathrm{~mm}$ chiếm $40 \%$, lệch phải $4 \mathrm{~mm}$ chiếm $44 \%$. Tỷ lệ phát hiện nụ cười mất thẩm mỹ khi đường giữa lệch trái $3 \mathrm{~mm}$ là $22 \%$, lệch phải $3 \mathrm{~mm}$ là $20 \%$, lệch trái $2 \mathrm{~mm}$ là $8 \%$, lệch phải $2 \mathrm{~mm}$ là $4 \%$.

Không ai thấy nụ cười mất thẩm mỹ khi đường giữa không lệch, lệch $1 \mathrm{~mm}$ sang trái và phải. Tỷ lệ đối tượng không phát hiện nụ cười mất thẩm mỹ khi chỉnh lệch đường giữa sang trái và phải chiếm tỷ lệ $30 \%$ và $32 \%$.

Bảng 1: So sánh khoảng chấp nhận lệch dường giữa theo hướng lệch

\begin{tabular}{|c|c|c|c|c|}
\hline & GTTB & SD & GTNN & GTLN \\
\hline Lệch trái & 2,92 & 0,92 & 1 & 4 \\
\hline Lệcch phải & 3,04 & 0,83 & 1 & 4 \\
\hline p & \multicolumn{5}{|c|}{0,28} \\
\hline
\end{tabular}

Nhận xét: Khoảng chấp nhận lệch đường giữa khi hướng lệch sang trái là $2,92 \pm 0,92 \mathrm{~mm}$ và lớn hơn so với lệch sang phải là $3,04 \pm$ $0,83 \mathrm{~mm}$. Sự khác biêt này không có ý nghĩa thống kê với $p>0,05$ (Kiểm định T-test ghép cặp)

Bảng 2: So sánh khoảng chấp nhận lệch đường giữa theo giới.

\begin{tabular}{|c|c|c|c|c|}
$\begin{array}{c}\text { Khoảng } \\
\text { chấp nhận }\end{array}$ & GTTB & SD & GTNN & GTLN \\
\hline Nam & 3,02 & 0,8 & 1 & 4 \\
\hline Nữ & 2,94 & 0,79 & 1 & 4 \\
\hline Tống & 2,98 & 0,78 & 1 & 4 \\
\hline P & \multicolumn{4}{|c|}{0,72} \\
\hline
\end{tabular}

Nhận xét: Trong 50 đối tượng nghiên cứu gồm 25 nam và 25 nữ, khoảng chấp nhận lệch đường giữa mà không ảnh hưởng tới thẩm mỹ nụ cười trung bình là 2,98 $\pm 0,78 \mathrm{~mm}$; nam giới chấp nhận lệch đường giữa $3,02 \pm 0,8 \mathrm{~mm}$ cao hơn ở nữ $2,94 \pm 0,79 \mathrm{~mm}$. Sự khác biệt này không có ý nghĩa thống kê với $p>0,05$ (Kiểm định T-test độc lập).

\section{BÀN LUẬN}

Theo biểu đồ 1 , các ảnh chụp nụ cười khi không chỉnh lệch đường giữa và ảnh chụp nụ cười sau khi chỉnh lệch đường giữa mức độ nhỏ $1 \mathrm{~mm}$ sang trái/ phải đều không gây mất thẩm mỹ, tỷ lệ phát hiện mất thẩm mỹ tăng dần theo mức độ lệch đường giữa, khi lệch trái $2 \mathrm{~mm}$ tỷ lê phát hiện $8 \%$, lệch phải $2 \mathrm{~mm} 4 \%$, lệch trái trái $3 \mathrm{~mm} 22 \%$, lệch phải $3 \mathrm{~mm}$ là $20 \%$, lệch trái $4 \mathrm{~mm}$ chiếm $40 \%$, lệch phải $4 \mathrm{~mm}$ chiếm $44 \%$. Tỷ lệ phát hiện càng cao, khi mức độ lệch càng lớn phù hợp với kết quả nghiên cứu của Harold $\mathrm{S}$. Cardash. Tuy nhiên, tỷ lệ đối tượng không phát hiện nụ cười mất thẩm mỹ khi chỉnh lệch đường giữa sang bên trái và phải cũng cao lần lượt $30 \%$ và $32 \%$.

Nguyên nhân khiến nụ cười mất thẩm mỹ bao gồm răng, lợi, môi, nguyên nhân khác và không rõ nguyên nhân. Kết quả cho thấy, trong các ảnh được cho là mất thẩm mỹ, hầu hết nguyên nhân do răng $(>75 \%)$, ngoài ra có tỷ lệ nhỏ do nguyên nhân khác và không rõ nguyên nhân. Kết quả này có thể giải thích do ảnh được sử dụng trong nghiên cứu đảm bảo thẩm mỹ tương đối hài hòa nên khi dùng phần mềm chỉnh lệch đường giữa, đối tượng nghiên cứu sẽ phát hiện nụ cười mất thẩm mỹ và chọn ra được nguyển nhân do răng chứ không bị nhiễu bởi các yếu tố khác gây khó khăn trong đánh giá.

Trong 50 đối tượng nghiên cứu gồm 25 nam và 25 nữ, khoảng chấp nhận lệch đường giữa mà không ảnh hưởng tới thẩm mỹ nụ cười trung bình $2,98 \pm 0,78 \mathrm{~mm}$. Kết quả này phù hợp với kết quả nghiên cứu của Ker và cộng sự [4] với khoảng chấp nhận lệch đường giửa 2,9mm. Điều này do đối tượng và phương pháp nghiên cứu của hai nghiên cứu giống nhau, đều được thực hiện trên người không có kiến thức chuyền mồn về răng hàm mă̆t. Cả hai nghiên cứu đều sử dụng phương pháp chọn ảnh trong một dãy các biến để tìm ra khoảng chấp nhận của lệch đường giữa thay vì sử dụng thang điểm truyền thống để đánh giá ảnh.

Tuy nhiên, khoảng chấp nhận trong nghiên cứu của chúng tôi nhỏ hơn, hay nói cách khác người đánh giá trong nghiên cứu có phần khắt khe hơn so với các nghiên cứu của Vincent $O$. Kokich năm 1999, Pinho S và cộng sự năm 2007 [5]. Kết quả của hai nghiên cứu trền cho thấy 
người không có chuyên môn không phát hiện được sai lệch đường giữa với khoảng lệch đến $4 \mathrm{~mm}$. Ngược lại, so sánh với các kết quả của Chris D. Johnston năm 1999, Tarulatha R.Shyagali nghiên cứu năm 2008 và Trần Phải Phụng và Đổng Khắc Thẩm năm 2013 và Catherine McLeod năm 2011 [2],[4], [6], [7], khoảng chấp nhận lệch đường giữa mà không gây mất thẩm mỹ் nụ cười trong nghiên cứu của tôi lớn hơn giá trị chấp nhận của các nghiên cứu trên. Cụ thể trong nghiên cứu của Tarulatha R.Shyagali cho thây lệch đường giữa từ $2 \mathrm{~mm}$ trở nên đã bị cho mất thẩm mỹ bởi cả nha sĩ và người không có chuyên môn, trong nghiên cứu của Chris D. Johnston tỷ lệ người không có chuyên môn cho điểm kém thẩm mỹ ở nụ cười có đường giữa lệch từ $2 \mathrm{~mm}$ là $56 \%$ và trong nghiên cứu của Trần Phải Phụng và Đổng Khắc Thẩm cho thấy người ngoài ngành chấp nhận khi đường giữa lệch đến $2,5 \mathrm{~mm}$ và trong nghiên cứu của Catherine McLeod khoảng chấp nhận độ lệch đường giữa là $1,83 \mathrm{~mm}$. Khoảng chấp nhận lệch đường giữa có sự khác biệt lớn giữa các nghiên cứu, điều này được giải thích là do có sự khác biệt giữa các nghiên cứu, đặc điểm của đối tượng nghiên cứu như chủng tộc, trình độ học vấn, điều kiện kinh tế - văn hóa, sự khác biệt còn thấy ở việc lựa chọn cỡ mẫu nghiên cứu và phương pháp tiến hành nghiên cứu.

Trong 50 đối tượng nghiên cứu gồm 25 nam và 25 nữ, khoảng chấp nhận lệch đường giữa mà không ảnh hưởng tới thẩm mỹ nụ cười ở nam giới là $3,02 \pm 0,8 \mathrm{~mm}$ cao hơn ở nữ là $2,94 \pm$ $0,79 \mathrm{~mm}$. Tuy nhiên sự khác biệt này không có ý nghĩa thống kê với $p>0,05$.

Chúng tôi cũng tiến hành so sánh, đánh giá mức độ chấp nhận với hai hướng lệch đường giữa khác nhau, kết quả thu được khoảng chấp nhận lệch đường giữa khi hướng lệch sang trái là $2,92 \pm 0,92 \mathrm{~mm}$ và lớn hơn so với lệch sang phải là $3,04 \pm 0,83 \mathrm{~mm}$. Sự khác biệt này không có ý nghĩa thống kê với $p>0,05$.

Để đánh giá sự khác biệt về khoảng chấp nhận lệch đường giữa của đổi tượng nghiên cứu theo địa lý, chúng tôi chia vùng địa lý sinh sống theo 3 nhóm. Khu vực 3 là các quận nội thành của thành phố trực thuộc trung ương, khu vực 2 là các thị xã, thành phố trực thuộc tỉnh; các thị xã; các thị xã, huyện ngoại thành của thành phổ trực thuộc trung ương, còn lại là khu vực 1 là các xã/ phường khó khăn thuộc vùng dần tộc và miên núi theo quy định hiện hành. Các đối tượng nghiên cứu ở khu vực 3 , khoảng chấp nhân là thấp nhất 2,84 $\pm 0,82 \mathrm{~mm}$, các đối tượng ngiên cứu ở khu vực 1 có khoảng chấp nhận cao nhất là $3,32 \pm 0,64 \mathrm{~mm}$. Tuy nhiên sự khác biệt này không có ý nghĩa thống kê.

So sánh khoảng chấp nhận lệch đường giữa theo trình độ học vấn, trong nghiên cứu này có 11 đối tượng trình độ học vấn cấp ba, có 39 đối tượng trình độ cao đẳng, đại học trở lên. Các đối tượng nghiên cứu trình độ cấp 3 chấp nhận khoảng lệch đường giữa cao hơn so với các đối tượng có trình độ cao đẳng, đại học trở lên lần lượt là $3,41 \pm 0,54 \mathrm{~mm}$ và $2,86 \pm 0,81 \mathrm{~mm}$. Sự khác biệt này có ý nghĩa thống kê với $p<0,05$.

Từ bảng 3.11 cho thây khoảng chấp nhận lệch đường giữa khác nhau ở các nhóm tuổi. Ở nhóm tuổi từ 25 đến 34, người đánh giá chấp nhận khoảng lệch đường giữa là thấp nhất $(2,9$ $\pm 0,79 \mathrm{~mm})$, tiếp theo là nhóm tuổi từ 35 đến 44 là 2,96 $\pm 0,92 \mathrm{~mm}$, khoảng chấp nhận lệch đường giữa cao nhất là $3,36 \pm 0,38 \mathrm{~mm}$ ở nhóm tuổi trên 45. Điều này cho thấy, tuổi càng cao, người đánh giá càng dễ tính hơn trong việc chấp nhận các sai lệch đường giữa trong thẩm mỹ nụ cười. Tuy nhiển, sự khác biệt này không có ý nghĩa thống kê với $\mathrm{p}>0,05$.

So sánh khoảng chấp nhận lệch đường giữa giữa các đối tượng đã từng đi điêu trị răng miệng và chưa từng điều trị răng miệng thây sự có sự khác biệt. Trong 50 đối tượng nghiên cứu, có 37 đối tượng đã từng điều trị răng miệng. Nhóm đối tượng chưa từng điêu trị răng miệng chấp nhận khoảng lệch đường giữa lớn hơn so với nhóm đối tượng đã từng điêu trị răng miệng. Điều này có thể thấy, ở các đối tượng đã điều trị răng miệng có sự quan tâm đến sức khỏe, thẩm mỹ răng miệng cụ thể là mức độ sai lệch đường giữa hơn nhóm đối tượng chưa điều trị răng miệng bao giờ. Tuy nhiên sự khác biệt này khônng có ý nghĩa thống kê với $p<0,05$.

\section{KẾT LUÂN}

Lệch đường giữa là một thông số ảnh hưởng đến thẩm mỹ nụ cười khi lệch lớn hơn 2,98 \pm $0,78 \mathrm{~mm}$. Mức độ ảnh hưởng đến thẩm mỹ nụ cười của lệch đường giữa bị ảnh hưởng giới, tuổi và trình độ học vấn của người đối diện. Nghiên cứu này cung cấp cho các bác sĩ chỉnh nha một bằng chứng lâm sàng để từ đó lựa kế hoạch điều trị chỉnh nha phù hợp với từng trường hợp cụ thể nhằm có được kết quả điều trị tốt nhất.

\section{TÀI LIẸU THAM KHẢO}

1. Van der Geld $P_{\text {., }}$ Oosterveld P., Van Heck G. và cộng sự. (2007). Smile Attractiveness: Selfperception and Influence on Personality. Angle Orthod, 77(5), 759-765. 
2. Trân Phải Phụng và Đổng Khắc Thẩm (2013). Cảm nhận của người trong và ngoài ngành răng hàm măt về môtt số đăc điểm thẩm mỹ nu cười: đường giữa hàm trên, độ nghiêng mặt phẳng nhai và đướng cười. Tap Chí Học Viêt Nam, 411, 58-67.

3. Zhang Y., Xiao L., Li J. và cộng sự. (2010) Young People's Esthetic Perception of Dental Midline Deviation. Angle Orthod, 80(3), 515-520.

4. Pinho S., Ciriaco C., Faber J. và cộng sự (2007). Impact of dental asymmetries on the perception of smile esthetics. Am J Orthod Dentofacial Orthop, 132(6), 748-753.
5. A.J. Ker, Richard Chan, và Henry W. Fields (2008). Esthetics and smile characteristics from the layperson's perspective A computer-based survey study. Am J Orthod, 139, 1318-1327.

6. Tarulatha R. Shyagali, B. Chandralekha, và Deepak P. Bhayya (2008). Are ratings of dentofacial attractiveness influenced by dentofacial midline discrepancies?. Aust Orthod J, 24(2), 91-95.

7. McLeod C., Fields H.W., Hechter F. và cộng sư. (2011). Esthetics and smile characteristics evaluated by laypersons: A comparison of Canadian and US data. Angle Orthod, 81(2), 198-205.

\section{NHỮNG VẤN ĐỀ CẦN LƯU Ý TRONG CHĂM SÓC BÊNH NHÂN SAU PHẪU THUÂT CHỈNH HÌNH XƯƠ'NG HAI HÀM TẠI KHOA RĂNG HÀM MẶT BỆNH VIỆN ĐẠI HỌC Y HÀ NộI: BÁO CÁO CHÙM CA BỆNH}

Phùng Thị Huyền' ${ }^{1}$, Hoàng Thị Thảo¹, Nông Thị Phương Thảo, Phạm Quang Dương ${ }^{2}$, Nguyễn Trường Minh ${ }^{1,3}$

\section{TÓM TẮT}

Chăm sóc bệnh nhân sau phẫu thuật chỉnh hình xương hai hàm rất quan trong trong đảm bảo kết quả phẫu thuật. Việc nắm chắc kiến thức và kỹ năng đưa ra kế hoach chăm sóc toàn diên với muc tiêu điều trị bệnh nhần với kết quả tốt nhất là điều cần thiết. Chúng tôi trình bày kế hoạch chăm sóc và kết quả chăm sóc của một số trường hợp lâm sàng sau phâu thuât chỉnh hình xương và điểm qua về các chú ý trong chăm sóc về dinh dưỡng và vệ sinh răng miệng

Tư khóa: Chăm sóc sau phẫu thuật, phẫu thuật chỉnh hình xương

\section{SUMMARY}

\section{CLINICAL NOTES FOR POST OPERATIVE CARE IN BIMAXILLARY ORTHOGNATHIC SURGERY PATIENT AT ODONTO- STOMATOLOGY DEPARTMENT, HANOI MEDICAL UNIVERSITY HOSPITAL 2020}

Postoperative patient management is critical for high quality patient treatment and predictable patient outcomes in orthognathic surgery. In order to provide consistent, high quality outcomes for patients a thorough understanding and ability to implement postoperative management protocols and strategies must be gained. In this article, several bimaxillary orthognathic surgery cases are presentend with some clinical notes in nutritional and oral hygiene care.

Keywords: Postoperative care, orthognathic surgery

${ }^{1}$ Bênh viên Đai hơ Y Hà Nôi

${ }^{2}$ Bệnh viện Răng-Hàm-Mặt Trung ương Hà Nội

3 Viên Đào tạo Răng-Hàm-Mặt, Đại hoc Y Hà Nội

Chịu trách nhiệm chính: Nguyễn Trường Minh

Email: nguyentruongminh@hmu.edu.vn

Ngày nhận bài: 17.11.2020

Ngày phản biên khoa hoc: 23.12.2020

Ngày duyệt bài: 4.01.2021

\section{TỔNG QUAN}

Phẫu thuật chỉnh hình xương (Orthognathic surgery) là phẫu thuật chỉnh sửa các bất thường về xương của xương hàm trên, xương hàm dưới hoăc cả hai xương với mục tiêu sửa chữa các biến dạng của xương nhằm cải thiên thẩm mỹ và chức năng của bệnh nhân. ${ }^{1}$ Phấu thuật chỉnh hình xương gồm có phẫu thuật cắt xương hàm trên theo đường LeFort I, phẫu thuật chẻ dọc cành lên xương hàm dưới (BSSO) và phẫu thuật tạo hình cằm (Genioplasty) (hình 1-0).

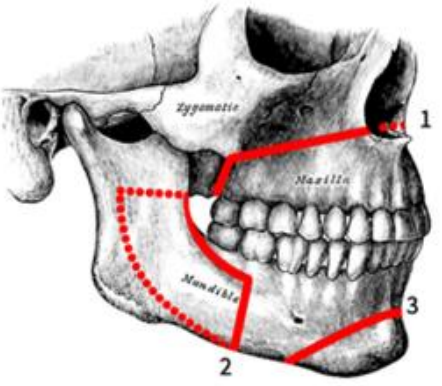

Hinh 1-0

Bệnh nhân phẫu thuật chỉnh hình xương thường nằm viện trong thời gian ngắn từ 5 đến 7 ngày. ${ }^{2}$ Kế hoạch chăm sóc không chỉ chăm sóc các nhu cầu của người bệnh trong giai đoạn tiền phẫu mà còn điều chỉnh kế hoạch đề phòng nếu hậu phẫu kéo dài. Sắp xếp kế hoạch chăm sóc và giáo dục sức khỏe phù hợp với từng giai đoạn trong phấu thuật chỉnh hình xương sẽ đóng góp tích cực vào mức đô tự chăm sóc của người bệnh cũng như sự hỗ trợ chăm sóc của người nhà người bệnh. 